\title{
Exame criminológico e psicologia: crise e manutenção da disciplina carcerária ${ }^{\star}$

\author{
Jefferson Cruz Reishoffer, Pedro Paulo Gastalho de Bicalho $\star \star$ \\ Universidade Federal do Rio de Janeiro, Rio de Janeiro, RJ, Brasil
}

Resumo

Em 2003, a Lei $n^{\circ} 10.792$ retirou a obrigatoriedade de realização do exame criminológico, no âmbito da execução penal brasileira, alterando o rol de requisitos para fins de concessão de livramento condicional e de progressão de regime. Contudo, tal alteração legal não produziu efeitos significativos nas esferas judiciárias, pois, mais de dez anos depois, ainda há grande quantidade de solicitações para realização de tais exames como principal subsídio à decisão de juízes. Este artigo coloca em análise as estratégias de saber e os exercícios de poder que mantêm tais avaliações e a lógica criminalizante presente nos procedimentos carcerários, promovendo questionamentos à Psicologia, aos princípios presentes em seu código de ética e ao compromisso social da profissão.

Palavras-chave: criminologia; avaliação; psicologia criminal.

\section{Criminological examination and psychology: crisis and maintenance of prison discipline}

\begin{abstract}
In 2003 the law 10,792 removed the obligation to carry out the criminological examination, within the Brazilian criminal enforcement by changing the list of requirements for opportunity of parole and progressive sentencing. However, this legislative amendment appears not to have produced significant effects on judicial levels and more than ten years later, the number of requests to perform such tests with maintaining its primary function of supporting the decision of the judges is still huge. This article aims the strategies of knowing and exercise of power in comments directed the examination and the criminalizing logic present in the prison procedures, making questions to Psychology and the principles in the ethics and the social commitment of the profession.
\end{abstract}

Keywords: criminology; evaluation; criminal psychology.

\section{Introdução - A "Vergonha de Punir" e a Prática do Exame}

A partir das Revoluções Liberais do séc. XVIII, o aparelhamento da instituição-prisão para controle da criminalidade adquiriu características de necessidade e de obviedade de forma muito rápida. Segundo Foucault (1997), podemos entender que a detenção como forma prioritária de punição segue em paralelo com transformações nas estratégias do poder de punir que, do século XVIII para o XIX, testemunharam a passagem das sociedades ditas de soberania para as sociedades disciplinares. ${ }^{1}$ Em oposição ao poder de punir - excessivo, incerto e desigual - disponível nas mãos do soberano tornou-se imperativo realizar uma nova economia do poder de castigar: torná-lo mais regular, necessário e universal, além inseri-lo de forma profunda e extensível a todo o corpo social. Desta forma, os grandes rituais de castigo, os suplícios, destinados a provocar terror e exemplo, "desaparecem diante da exigência de uma universalidade punitiva concretizada no sistema penitenciário" (FOUCAULT, 2012, p. 33).

Com as mudanças na estrutura social e nas legislações penais, a penalidade moderna passa a orientar-se cada vez mais em direção ao homem criminoso e não ao

\footnotetext{
$\star$ Fontes de Financiamento: CNPq e FAPERJ

$\star \star$ Endereço para correspondência: Universidade Federal do Rio de Janeiro, Instituto de Psicologia. Av. Pasteur, 250 - Pavilhão Nilton Campos - Campus Praia Vermelha - Urca. - Rio de Janeiro, RJ - Brasil. CEP: 22290240. E-mail: projefferson@gmail.com, ppbicalho@ufrj.br

O poder disciplinar surge como estratégia política para adestrar as massas, utilizar as forças de trabalho dispersas e promover o adestramento do corpo, utilizando-se de uma forma mais econômica, porém mais eficaz de controle. É um exercício do poder que substitui as formas violentas e descontínuas das sociedades de soberania, funcionando de um modo mais discreto, porém de forma permanente e espalhados por todo o corpo social através de suas diversas instituições.
}

fato definido como crime. A prisão se solidificou, dentro de uma sociedade disciplinar, principalmente por sua função técnica de correção de indivíduos - sua obviedade técnico-disciplinar (REISHOFFER; BICALHO, 2015). Contudo, para o sistema penal cumprir a função corretiva, necessário seria conhecer não apenas o crime e a lei, mas, necessariamente, o sujeito criminoso: suas paixões, suas motivações, seu ambiente e possíveis enfermidades, modulando a pena de acordo com estes novos elementos.

O julgamento não estaria mais orientado para o resultado de um inquérito: conhecimento do autor, da infração e da lei para aplicação de uma sanção penal. Outro tipo de saber foi necessário ser introduzido no mecanismo penal: "O que significa este crime?", "Quem é este criminoso?", "Qual grau de perigo representa?". Ou seja, "todo um conjunto de julgamentos apreciativos, diagnósticos, prognósticos, normativos, concernentes ao indivíduo criminoso encontrou acolhida no sistema de juízo penal" (Foucault, 1997, p. 21). A prisão enquanto penalidade inaugura uma forma de sanção que não se refere a uma infração, mas a um comportamento, a uma personalidade criminosa, que deve ser buscada no interior de uma história individual.

Assim, inaugura-se uma série de saberes, técnicas e discursos científicos que serão incorporados e estarão entrelaçados às práticas do poder de punir, necessários a esta permanente e constante avaliação do sujeito criminoso. A punição não funcionará mais como simples aplicação da lei, mas como técnica corretiva que busca, além de corrigir o sujeito criminoso, estabelecer as razões, motivações e determinações que engendraram a violação 
da lei, devendo ao juiz transferir sua responsabilidade exclusivamente punitiva aos técnicos encarregados em exercer de forma efetiva a execução penal.

$\mathrm{O}$ poder de julgar foi, em grande parte, transferido a instâncias e personagens extrajurídicos ou a "juízes em anexo": psicólogos, criminólogos, psiquiatras, assistentes sociais, sociólogos. "Existe na justiça moderna e entre aqueles que a distribuem uma vergonha de punir, que nem sempre exclui o zelo; ela aumenta constantemente: sobre esta chaga pululam os psicólogos e o pequeno funcionário da ortopedia moral" (FOUCAULT, 1997, p. 14). O lado "humanitário" do sistema prisional consistiria em buscar a correção e a reinserção do criminoso, afastando-se da pura vingança e da retribuição violenta por parte do Estado.

E acima dessa distribuição dos papéis se realiza a negação teórica: o essencial da pena que nós, juízes, infligimos não creiais que consista em punir; o essencial é procurar corrigir, reeducar, "curar"; uma técnica de aperfeiçoamento recalca, na pena, a estrita expiação do mal, e liberta os magistrados do vil ofício de castigadores (FOUCAULT, 1997, p. 14).

A tecnologia penitenciária torna-se independente das medidas penais da Justiça, e estas, caso intervenham durante a execução, devem pautar-se, a partir de então, no conhecimento que será adquirido do sujeito criminoso no itinerário de sua execução penal. De um lado, a psiquiatria será convocada para determinar o grau de responsabilidade do autor no momento do ato criminoso - se no momento de sua infração tinha discernimento suficiente para entender a ilicitude de seu ato, estando assim passível, ou não, à sanção penal ou a medidas de internação/contenção e, de outro, um conjunto de técnicos do cárcere avaliará os efeitos da sanção penal sobre o indivíduo e deverá decidir se ele merece ser posto em liberdade (KOLKER, 2004).

O exame, como forma ritual e científica de fixar diferenças individuais, amarrou cada indivíduo à sua própria singularidade, indicando a aparição de uma nova modalidade de poder em que cada um recebe como status permanente uma individualidade estatutariamente ligada aos traços, às medidas, aos desvios e às avaliações que caracterizam o indivíduo e fazem dele, de todo modo, um "caso". A própria prática do exame cria um objeto de estudo para o saber e um objeto de intervenção para o poder (FOUCAULT, 1997).

\section{O Positivismo como princípio}

Neste momento estavam criadas as condições de possibilidade para as ciências humanas formarem, construírem e consolidarem seus saberes sobre as individualidades, tornando a prisão, com suas características mais marcantes de instituição total, o local por excelência de exercício do poder disciplinar. ${ }^{2}$ Aliadas às condições de vigilância e exame dentro dos espaços de confinamento, as ciências humanas e criminológicas emergentes precisavam de um projeto que conferisse validade e fidedig-

\footnotetext{
${ }^{2}$ A prisão deve ser um aparelho disciplinar exaustivo em vários sentidos: deve tomar a seu cargo todos os aspectos do indivíduo, seu treinamento físico, sua aptidão para o trabalho, seu comportamento cotidiano, sua atitude moral, suas disposições; a prisão, muito mais que a escola, a oficina ou o exército, que implicam sempre numa certa especialização, é “onidisciplinar” (FOUCAULT, 1997, p. 264).
}

nidade para subsidiar de forma legítima a justiça penal. Assim, buscaram aliar-se ao então modelo hegemônico de verdade: o discurso positivista ${ }^{3}$ empregado nas ciências naturais, pretendendo então encontrar, tanto no homem como na sociedade, as mesmas leis e regras que determinavam a ordem e o desenvolvimento dos fenômenos da natureza.

Será a combinação das relações de poder instaladas no interior dos espaços de reclusão e a própria produção de um discurso legitimado como verdadeiro sobre o indivíduo que criará as condições de possibilidade das ciências do homem e da produção do próprio indivíduo (BICALHO; KASTRUP; REISHOFFER, 2012, p. 58).

Da Criminologia Positivista construir-se-á o principal discurso que realizará a transformação dos fundamentos do direito penal liberal em direção ao discurso cientificista. Pelo Liberalismo todo cidadão seria considerado responsável e parte integrante do pacto social e, em caso de transgressão das leis - consideradas produtos de um consenso democrático - sua punição, previamente determinada, deveria ser proporcional ao dano causado, garantindo a supremacia da sociedade contra um de seus indivíduos. No entendimento dos criminólogos positivistas, "por prescindir de bases científicas nas quais se fundamentar, o direito perdeu-se em considerações metafísicas e, principalmente, descuidou-se de sua tarefa básica de defender a sociedade" (RAUTER, 2003, p. 26).

Tornava-se necessário que o Direito Penal avançasse em direção a critérios científicos para que cada sociedade pudesse estudar seus criminosos e, a partir de tal conhecimento, defender-se de forma natural contra aquilo que era considerado uma ameaça. O Direito Penal deveria deixar a apreciação dos delitos e das leis para as autoridades judiciárias, enquanto os criminólogos se ocupariam de estudar o criminoso e seus crimes em seus aspectos psicológicos e sociais, buscando transformar a punição em um meio eficaz de combater a anormalidade do mesmo, segundo seus padrões de periculosidade. Se as penas não conseguissem recuperar ou intimidar os criminosos, tal fracasso dever-se-ia à própria anormalidade individual do infrator, o que, aparentemente, justificava os altos índices de reincidência e o fracasso da reinserção social.

Com a prisão tornando-se a penalidade privilegiada para a implementação de uma prática corretiva sobre os criminosos - em substituição ao mero poder de punir dos juízes e em concomitante produção de um saber positivista específico sobre a criminalidade -, tornam-se cada vez mais frequentes e obrigatórias as oportunidades de promover a avaliação do sujeito infrator no decorrer do cumprimento de sua pena. Para a produção de tais exames foi destinada uma posição específica a psicólogos, assistentes sociais e psiquiatras dentro da maquinaria da prisão como produtores de laudos e pareceres, numa in-

${ }^{3}$ A disciplinarização da ciência psicológica remonta ao final do século XIX, quando esse campo de saber passa a operar dentro de uma regularidade científica que buscou conferir legitimação a seu discurso dentro de um regime de verdade hegemônico, a saber, a ordem científica de cunho positivista. "[...] Esse empreendimento levou a Psicologia a alinhar-se aos pressupostos positivistas de ciência que exigiam de seus pretendentes a objetividade, a neutralidade, a experimentação e a generalização" (BICALHO; KASTRUP; REISHOFFER, 2012, p. 57). 
cessante postura avaliativa que tinha como alvo o sentenciado em sua posição de adaptação às regras de conduta e disciplina do cárcere.

Neste artigo são focalizados os conflitos políticos recentes que envolveram importantes atores da execução penal no Brasil: magistrados, promotores, defensores públicos, psicólogos que defendem a manutenção do exame psicológico como condição para a concessão de benefícios e o Conselho Federal de Psicologia, buscando qualificar a atividade do psicólogo, afastando-o de uma prática meramente classificatória e pericial, atentando para o cumprimento dos princípios ético-políticos da responsabilidade social da profissão. A prática do psicólogo será o cerne da discussão neste artigo pela formação e atuação dos autores, mas os questionamentos e críticas não excluem e também se orientam às práticas igualmente acríticas de assistentes sociais, psiquiatras e juízes, entre outros atores sociais, na avaliação criminológica do infrator durante a execução da pena.

\section{O Positivismo entre nós: o código, as leis e as resoluções da Psicologia}

Buscando um resgate histórico dos dispositivos legais que regulamentam a situação penal no Brasil, a elaboração do nosso Código Penal de 1940 (BRASIL, 1940) foi o principal instrumento que trouxe a forte influência dos ideais da Escola Criminológica Positivista ao Direito Penal, manifestando-se claramente no tocante à introdução da personalidade do criminoso, seus antecedentes, conduta social, bem como os motivos para o delito como elementos relevantes para a quantificação da pena aplicada. Generaliza-se uma tendência ao considerar a pessoa do criminoso em seus aspectos históricos, sociais e subjetivos como diretrizes para efetivar o princípio da individualização da pena. Ao lado deste, o Código Penal de 1940 também irá consagrar o sistema do duplo binário, incorporando como possíveis sanções as chamadas "medidas de segurança" para os criminosos vistos como doentes mentais perigosos, não passíveis de pena, mas sim de tratamento específico. Para estes será adotada a novidade que marca a influência positivista definitiva em nosso meio: o critério da periculosidade. O sistema era duplo, pois congregava, de um lado, a pena, de caráter retributivo, aplicada segundo o grau de culpa do sujeito e a gravidade do seu ato; e de outro, a medida de segurança calcada na avaliação do grau de periculosidade do acusado. Esta última, de caráter preventivo, apresentava uma dupla finalidade: a defesa social, por meio da segregação dos considerados perigosos; e o tratamento destes indivíduos, com o objetivo de anular sua periculosidade (MECLER, 2010).

Assim, na exposição de motivos ao Código Penal de 1940, é definida a influência positivista:

5. É notório que as medidas puramente repressivas e propriamente penais se revelaram insuficientes na luta contra a criminalidade, em particular contra as suas formas habituais. Ao lado disto, existe a criminalidade dos doentes mentais perigosos. Estes, isentos de pena, não eram submetidos a nenhuma medida de segurança ou custódia senão nos casos de imediata periculosidade. Para corrigir a anomalia, foram instituídas, ao lado das penas, que têm finalidade repressiva e intimidante, as medidas de segurança. Estas, embora aplicáveis em regra post delictum, são essencialmente preventivas, destinadas à segregação, vigilância, reeducação e tratamento dos indivíduos perigosos, ainda que moralmente irresponsáveis (OLIVEIRA apud KOLKER, 2004, p. 191).

Com o processo de incorporação dos critérios subjetivos nas práticas judiciárias, aos juízes ficavam determinadas duas possibilidades, a considerar pela personalidade e condições mentais do sujeito criminoso: decidir pela aplicação apenas das medidas de segurança a um sujeito considerado "louco", irresponsável, porém altamente perigoso ou, no caso da também possibilidade de aplicação de pena, graduar sua quantidade de acordo com os antecedentes, subjetividade, circunstâncias e consequências do crime, determinando inclusive casos limítrofes de semi-imputabilidade (considerados parcialmente responsáveis). Com as medidas de segurança aplicadas cumulativamente com as penas, inaugura-se naquele momento uma espécie de pena-tratamento, que dever-se-ia ser cumprida em manicômios judiciários, e seus necessários exames correlatos, sustentados pela noção de periculosidade, produto da ciência positivista criminológica.

Além dos loucos "infratores", toda uma classe de criminosos passa a ser monitorada pelo dispositivo da periculosidade: os limítrofes, os reincidentes, criminosos com vasta ficha criminal, os praticantes de crimes contra os costumes, criminosos com registros de violência e crueldade, etc. Como pontua Rauter (2003), na prática, toda esta classe de criminosos passou a ter como destino penas mais prolongadas e arbitrárias, devido à inexistência das supostas instituições de tratamento, já que a intenção primeira da aplicação das medidas de segurança era a vigilância e não o tratamento, numa estratégia de ampliação do poder repressivo do Estado em nome da ciência:

Reconhecem os próprios criminólogos que as prisões não serão reformadas (ou o serão em alguns pontos apenas), que do misto entre hospital e prisão ficaremos com a velha prisão. E com a adoção da medida de segurança ao lado das penas teremos na prática um aumento destas, sem nem sequer uma feição curativa, aumento este baseado no arbítrio do juiz, que julga finalmente sem lei (RAUTER, 2003, p. 73).

Foram introduzidos, também pelo "novo código", os chamados Exames de Verificação de Cessação de Periculosidade (EVCP), exames psiquiátricos aplicados ao final de um prazo estabelecido, impostos aos julgados considerados especialmente perigosos e semi-imputáveis, para determinar a cessação de "sua" periculosidade e os efeitos de um tratamento penal reconhecidamente inexistente. Um laudo desfavorável, obviamente, significava o prolongamento do tempo de reclusão e de suposto tratamento. Percebemos que a influência positivista que cria os EVCPs ainda encontra-se presente nos exames criminológicos da atualidade, buscando determinar os efeitos de um tratamento penal nas subjetividades dos sentenciados para que seja possível prever sua suposta e pretendida reinserção social. 
Assim, com a introdução da noção de subjetividade e das ciências humanas no âmbito do judiciário brasileiro, a recém-inaugurada ciência psicológica encontraria aos poucos seu espaço de atuação nas prisões brasileiras e nos então denominados manicômios judiciários. Segundo Badaró-Bandeira et al. (2006), a inserção da Psicologia no sistema penal brasileiro aconteceu no estado do Rio de Janeiro, na década de 60 , logo após a regulamentação da profissão no Brasil, materializada com a promulgação da lei 4.119 (BRASIL, 1962) pelo então presidente João Goulart, em 27 de agosto de 1962. Psicólogos ingressaram no Manicômio Judiciário Heitor Carrilho, com uma prática ligada principalmente à assistência, tratamento e acompanhamento dos "loucos infratores", considerados inimputáveis e que cumpriam as medidas de segurança. Já nos estabelecimentos prisionais, voltados aos reclusos em penas privativas de liberdade, a inserção foi acontecendo gradativamente no final da década de 70, onde o psicólogo participava do acompanhamento da individualização da pena por meio de atividades de classificação e acompanhamento do apenado (CONSELHO FEDERAL DE PSICOLOGIA [CFP]; MINISTÉRIO DA JUSTIÇA, 2007).

Em 1984, com a promulgação da Lei de Execuções Penais (LEP) (BRASIL, 1984), desaparece o sistema do duplo binário com a possibilidade de medidas de segurança aos condenados imputáveis, assim como deixam de existir os EVCPs para estes. Contudo, podemos asseverar que os princípios positivistas que criaram tais exames permaneceram presentes nos agora chamados "exames criminológicos". É mantida a necessidade do magistrado de buscar um respaldo dito científico para avaliar as condições subjetivas do sentenciado no momento da concessão de algum benefício penal. Assim, com a LEP, foi aperfeiçoado o princípio da individualização da execução penal, devendo o condenado ser classificado por meio de seus antecedentes e personalidade, de modo a ser indicado o tratamento penitenciário apropriado.

Para a adequada classificação, o condenado à privação de liberdade seria submetido ao exame criminológico que aconteceria em momentos distintos: no início da execução, para exame de sua personalidade como determinante do tipo de tratamento penal, e durante seu percurso, como forma de avaliar os efeitos do mesmo tratamento. Além disso, a partir do artigo 112 da LEP, três eram os requisitos necessários ao preso para concessão da progressão de regime: cumprimento de 1/6 (um sexto) da pena no regime anterior, comportamento que justificasse a concessão do "benefício" e exame criminológico de parecer favorável (realizado para avaliar a personalidade do criminoso, sua periculosidade, eventual arrependimento e a possibilidade reincidência) - realizado pelo psiquiatra, psicólogo e assistente social (CARDOZO, 2010).

Desta forma, institui-se, no interior das prisões, a Comissão Técnica de Classificação (CTC) responsável pela elaboração do programa individualizador da pena, além do acompanhamento e avaliação da execução penal, propondo assim, "as progressões e regressões de regime, bem como as conversões" (artigo $6^{\circ}$ da LEP). Em sua composição mínima, a CTC é presidida pelo diretor e composta por dois chefes de serviço, um psiquiatra, um psicólogo e um assistente social. Devido ao sistema progressivo da pena, as decisões judiciais de progressão de regime seriam motivadas e precedidas por pareceres da CTC e do exame criminológico4, quando julgado necessário.

Nesse sentido, a LEP criou dois mecanismos distintos para a atuação do psicólogo no sistema penal, como membro da CTC: um exame diagnóstico, com o objetivo de elaboração do projeto individualizador e um exame prognóstico, voltado à avaliação dos incidentes do processo de execução penal sob a justificativa de manifestação da subjetividade do encarcerado (CFP, 2010a). Ao psicólogo, segundo entendimento do legislador, estava caracterizada uma prática meramente classificatória e pericial, pois até a assistência à saúde 5 que está prevista no texto da LEP constitui-se do atendimento médico, farmacêutico e odontológico, sem nenhuma citação ao atendimento psicológico. Elaborar pareceres técnicos, realizar classificações, construir diagnósticos e estabelecer prognósticos - este foi o lugar formalmente reservado pelo legislador ao psicólogo que atua dentro do sistema penal.

Entretanto, em 2003, a Lei n 10.792 (BRASIL, 2003) retirou a obrigatoriedade do exame criminológico no âmbito da execução penal, excluindo-o do rol de requisitos necessários para fins de concessão de livramento condicional e progressão de regime. Segundo a nova redação o preso teria direito à progressão de regime depois de cumprir 1/6 da pena no regime anterior e ostentar bom comportamento carcerário, comprovado pelo diretor do presídio. Contudo tal alteração legal parece não ter produzido efeitos significativos nas esferas judiciárias, dada a quantidade enorme de solicitações para os exames pelas autoridades da execução penal e pela manutenção de sua função de subsídio à decisão dos juízes.

A modificação legal gerou tantas reações contrárias nas esferas judiciárias que o descontentamento promoveu um posicionamento do Supremo Tribunal Federal (STF) onde, em 2006, em julgamento de um pedido de Habeas Corpus (HC 88.052/DF, Rel. Min. Celso de Mello, DJ de 28/406), decidiu que, apesar de a lei ter excluído a referência ao exame criminológico, nada impediria que os magistrados determinassem a realização do mesmo, criando jurisprudência necessária a casos semelhantes, quando afirmou:

Não constitui demasia assinalar, neste ponto, não obstante o advento da Lei $\mathrm{n}^{\circ}$ 10.792/2003, que alterou o art. 112 da LEP - para dele excluir a referência ao exame criminológico -, que nada impede que os magistrados determinem a realização de mencionado exame, quando o entenderem necessário, consideradas as eventuais peculiaridades do caso, desde que o façam, contudo, em decisão adequadamente motivada (CARDOZO, 2010, p. 2).

${ }^{4}$ Alguns autores consideram importante estabelecer uma diferença entre "exame criminológico" e "parecer da CTC" determinando que ambos seguem princípios completamente diferentes. Este trabalho não contempla tal diferenciação pois busca destacar que não é a terminologia que está em primeiro plano e sim a características de constituírem-se, exames criminológicos ou não, como documentos que visam subsidiar a decisão dos juízes da execução a partir da realização de avaliações especializadas, tendo em vista que na composição da CTC, nem todos integrantes são profissionais de perícia científica.

${ }^{5}$ Artigo 14, Lei de Execuções Penais, 1984. 
O posicionamento, que foi acompanhado por decisões posteriores do Superior Tribunal de Justiça, trouxe a avaliação da necessidade da medida de volta à discricionariedade do magistrado, em uma clara tentativa de continuar aplicando o artigo 112 da LEP com sua antiga redação, principalmente nos casos em que as progressões de regime seriam negadas com base em exames criminológicos desfavoráveis (CARDOZO, 2010). Em poucas palavras, o exame criminológico não seria mais obrigatório, mas também não estaria proibido. Assim, foi fortalecido o viés conservador no âmbito judiciário, pois mesmo em face de uma mudança na esfera legal não foi possível produzir inovações nas práticas judiciárias. A lei mudou, mas continuou tudo como já estava.

Em alguns âmbitos, apenas retirou-se a terminologia "exame criminológico" e passou-se a referir a tais solicitações com nomes mais sutis como "pareceres técnicos" ou "relatórios penitenciários". A lógica permaneceu a mesma: subsidiar a decisão dos magistrados, tornando-se flagrante o clamor daqueles que defendem a necessidade de uma perspectiva psicológica, baseada em critérios técnico-científicos, para verificar a capacidade de reinserção social de cada preso. As inúmeras controvérsias geraram projetos de lei (PL 5613/2005, PL 1294/2007, PL 1764/2007, PL 6598/2009, PL 887/2011 e PL 4500/2011) 6 que tramitam no Congresso Nacional e que visam ressuscitar a previsão do exame criminológico para concessão de benefícios.

Diante de tal quadro, em 2009, os profissionais de psicologia que atuam no sistema prisional e a sociedade civil organizada ${ }^{7}$ encaminharam uma moção contra o exame criminológico, considerando que o mesmo:

[...] se constitui em uma prática não só burocrática, mas, sobretudo estigmatizante, classificatória e violadora dos direitos humanos. Além disso, sua realização se dá em condições objetivas que se caracterizam pela violação do Código de Ética dos profissionais envolvidos. Seu uso reifica discursos que sustentam a compreensão do conflito a partir de uma suposta natureza perigosa amparada em traços pessoalizados e não a partir de uma relação dialética entre indivíduo e produções sócio-históricas (CRP-05, 2009, p. 1).

Denunciam-se as condições em que são realizados tais exames (falta de profissionais, excesso de solicitações devido à superlotação carcerária, ausência de aprimoramento técnico) e as condições objetivas das prisões que, em sua grande maioria, afastam-se completamente das finalidades penais de ressocialização, fortalecendo apenas a segregação (REISHOFFER; BICALHO, 2015).

\footnotetext{
${ }^{6}$ Todos estes projetos de lei foram reunidos e apensados ao Projeto de Le 4500/2011 (BRASIL, 2011), de autoria do Senador Romeu Tuma (PFL/SP).

${ }^{7}$ Presentes no II Seminário Nacional do Sistema Prisional realizado nos dias 12,13 e 14 de novembro de 2008, na cidade do Rio de Janeiro, ratificando a proposta encaminhada por psicólogos ao Sistema Conselhos de Psicologia e ao Departamento Penitenciário Nacional (DEPEN) por ocasião do I Encontro Nacional dos Psicólogos do Sistema Prisional, em novembro de 2005. Tal proposta refere-se à importância da articulação de ações conjuntas entre as categorias profissionais responsáveis pelo exame criminológico, para entendimento junto aos Juízos da Execução Penal e gestores públicos sobre a aplicabilidade da Lei $10.792 / 2003$, no que se refere à extinção do exame criminológico (CRP-05, 2009, p. 1).
}

Contudo, mais importante que tais condições (circunstanciais), realiza-se uma crítica maior em relação aos princípios em que se baseiam tais avaliações, fundamentadas, como já visto, em uma suposta tendência criminosa, fruto de epistemologias marcadamente positivistas.

Assim, em 2010, o Conselho Federal de Psicologia (CFP), com base na Lei ${ }^{\circ} 10.792 / 2003,{ }^{8}$ editou a Resolução n. 009, de 29 de junho de 2010, que regulamentava a atuação do psicólogo no sistema prisional e estabelecia os princípios a serem seguidos pelo profissional. Buscava indicar formas de qualificar a atuação e garantir que os serviços fossem executados de maneira responsável e com qualidade, respeitando os princípios éticos que sustentam o compromisso social da profissão. Contudo, o que gerou grande discussão foi que, o CFP (2010b, art. $4^{\circ}$, a), dentre suas principais decisões, afirmou:

[...] é vedado ao psicólogo que atua nos estabelecimentos prisionais realizar exame criminológico e participar de ações e/ou decisões que envolvam práticas de caráter punitivo e disciplinar, bem como documento escrito oriundo da avaliação psicológica com fins de subsidiar decisão judicial durante a execução da pena do sentenciado.

A proibição dos psicólogos em realizar o exame criminológico e participar de decisões que envolvam punição gerou tantas controvérsias, ${ }^{9}$ que chegou a provocar reações do Ministério Público Federal, de várias autoridades judiciárias e até mesmo de alguns psicólogos. Os argumentos contrários iam desde a suposta proibição ao exercício da profissão no ambiente prisional até o desrespeito às decisões do STF e STJ que autorizam aos juízes à requisição da avaliação. Alguns psicólogos que decidiram acatar a decisão do Conselho chegaram a ser ameaçados de prisão pela não realização do exame criminológico (CFP, 2010a).

Pouco mais de dois meses depois, o CFP se viu forçado a suspender os efeitos da Resolução 009/2010, pelo prazo de seis meses, acatando uma Recomendação ${ }^{10}$ da Procuradoria da República no Rio Grande do Sul - Procuradoria Regional dos Direitos do Cidadão, que requereu a suspensão da resolução, sob pena de que o CFP respondesse à Ação Civil Pública, em caso de descumprimento.

Em meio às discussões, a gestão do Conselho Regional de Psicologia do Paraná, CRP-08, posicionou-se contrária à redação do texto que originaria a Resolução a profissão de psicólogo e na Lei $n^{\circ} 5766 / 71$ (BRASIL, 1971) que cria os Conselhos Federal e Regionais de Psicologia, destinados a orientar, disciplinar e fiscalizar o exercício da profissão de Psicólogo e zelar pela fiel observância dos princípios de ética e disciplina da classe.

${ }^{9}$ Para ilustrar a celeuma, neste período são publicados dois artigos, com posicionamentos opostos, em âmbitos jurídicos que traziam títulos curiosos: " $\mathrm{O}$ exame criminológico e a equivocada Resolução n. 9/2010 do Conselho Federal de Psicologia" de Renato Marcão (2010), membro do Ministério Público de São Paulo; e "O exame criminológico e a oportuna Resolução no 9/2010 do Conselho Federal de Psicologia", de Haroldo Caetano da Silva (2010), Promotor de Justiça em Goiânia (grifo nosso)

${ }^{10} \mathrm{~A}$ Recomendação da Procuradoria da República no Rio Grande do Sul Procuradoria Regional dos Direitos do Cidadão, também requereu a suspensão da Resolução do CFP n ${ }^{\circ}$ 010/2010. Em face disto, o CFP decidiu por não acatar a Recomendação de suspensão dos efeitos desta, que institui a regulamentação da Escuta Psicológica de Crianças e Adolescentes envolvidos em situação de 
009/2010. Esse posicionamento foi construído a partir do entendimento de que o assunto, até aquele momento, havia sido pouco discutido entre a categoria. Conforme o CRP-08, a Resolução 009/2010 contrariava orientações anteriores do próprio CFP, contempladas na publicação "Profissão Psicólogo - Legislação e Resoluções para a prática profissional" (CFP, 2007). Defendia-se que, dentre as especialidades a serem concedidas pelo CFP, estava a de psicólogo especialista em Psicologia Jurídica. Na descrição de suas atribuições como especialista, incluíam-se:

[...] fornecer subsídios ao processo judicial; orientar a administração e os colegiados do sistema penitenciário sob o ponto de vista psicológico; realizar avaliação das características da personalidade, através de triagem psicológica, avaliação de periculosidade e outros exames psicológicos no sistema penitenciário, para os casos de pedidos de benefícios, tais como transferência para estabelecimento semiaberto, livramento condicional e/ou outros semelhantes (CRP-08, 2010, p. 17).

A categoria profissional dos psicólogos encontrou-se dividida em meio à questão: para alguns profissionais, a proibição significava o amparo legal para que a prática dos psicólogos não permanecesse restrita às atividades avaliativas, encontrando respaldo jurídico e segurança do Conselho Profissional para desempenho de outras funções e iniciativas. Para outros, a Resolução 009/2010 trazia apreensão e insegurança quanto ao exercício profissional, com possível perda de espaço de atuação nos ambientes prisionais e, consequente, aprofundamento da defasagem do número de profissionais nos quadros funcionais em relação ao número de apenados. ${ }^{11}$

O CFP, buscando solução para as divergências, optou por suspender os efeitos da resolução até 2 de março de 2011, posteriormente estendendo o prazo para 2 de junho de 2011, ficando definido que até a reunião da Assembleia de Políticas, Administração e Finanças (APAF), instância deliberativa do Sistema Conselhos de Psicologia, fossem realizadas audiências públicas para debater o tema. Foram criados diversos Grupos de Trabalho (GT) nos diferentes conselhos regionais, bem como um nacional, para discussão da Resolução 009/2010, os motivos de sua suspensão e a possível reformulação de seu texto.

O GT Nacional, composto por representantes do CFP e de outros cinco Conselhos Regionais desenvolveu, então, uma minuta de resolução, apreciada na reunião da APAF, em maio de 2011, na qual ocorreu a aprovação da Resolução CFP 012/11, que revogou a de ${ }^{\circ}$ 009/10 (CRP-06, 2011). A nova resolução manteve a proibição da realização de avaliações para subsídio de decisão judicial, mas apenas "pela(o) psicóloga(o) que atua como profissional de referência para o acompanhamento da

violência na Rede de Proteção, porque entende que a inquirição de crianças e adolescentes em juízo, pelo psicólogo, não corresponde aos limites do exercício da Psicologia e aos limites éticos da profissão. Todavia, no dia 9 de julho de 2012, o Juiz da $28^{\mathrm{a}}$ Vara Federal da Seção Judiciária do Rio de Janeiro, decidiu pela suspensão da Resolução CFP n ${ }^{\circ}$ 10/2010 em todo Território Nacional. O Conselho Federal de Psicologia foi intimado no dia 16 de Julho de 2012 para cumprir a decisão proferida (CFP, 2012).

${ }^{11}$ Naquele momento, algumas instituições do Estado do Paraná contavam com dois psicólogos para 968 apenados (CRP-08, 2010). pessoa em cumprimento da pena ou medida de segurança, em quaisquer modalidades como atenção psicossocial, atenção à saúde integral, projetos de reintegração social, entre outros" (art. $4^{\circ}$, a), determinando que ficariam "vedadas a elaboração de prognóstico criminológico de reincidência, a aferição de periculosidade e o estabelecimento de nexo causal a partir do binômio delito-delinquente" (CFP, 2011, art. $4^{\circ}, \S 1^{\circ}$ ).

Um grande impasse estava instalado. De um lado, o Conselho Federal de Psicologia buscando qualificar a atividade do psicólogo dentro das prisões, afastando-o de práticas periciais que são realizadas acriticamente, buscando retirá-lo da função de reprodutor da lógica criminalizante do cárcere e que, hegemonicamente, produz atuações contrárias aos fundamentos que regem seu código de ética e aos princípios do compromisso social da profissão; e do outro, grande parcela do poder judiciário que mantém a posição de que é necessário tal respaldo "científico" no momento de uma decisão judicial que mudará a vida de diversas pessoas.

Muitas vezes, o profissional encontra-se em uma situação de delicada escolha: atender aos princípios fundamentais de seu código de ética, baseando-se no respeito à dignidade humana e à promoção dos direitos humanos, respeitando os limites de sua formação ou, ou por outro lado, cumprir uma "ordem judicial" cuja negativa pode gerar conflitos institucionais e problemas para o próprio (até ameaças de prisão por desrespeito à ordem judicial). Pois, como bem alertou Rauter (2007, p. 43): “Os psicólogos que atuam em prisões podem estar ameaçados caso não se proponham a reproduzir a engrenagem da instituição carcerária através de sua atuação".

\section{O exame - Sua crítica e sua eficácia}

Apesar de compreender o peso e a relevância, em termos profissionais, dos psicólogos estabelecerem questionamentos em torno de suas atuais condições de trabalho e exigir melhoria das mesmas, a crítica ao exame criminológico torna-se uma armadilha em caso de estar apenas direcionada às questões estruturais, institucionais e técnicas. Dentre estas críticas algumas fundamentam-se em argumentos que constituem falácias: 1) Que não é possível avaliar o mérito individual do preso, pois as cadeias superlotadas não oferecem o mínimo de direitos e dignidade, ou seja, o encarcerado não se reabilita porque as condições de cárcere são precárias, sendo assim a avaliação de seu mérito individual encontra-se prejudicada; 2) Que os problemas do exame dizem respeito a uma prática burocrática, lacônica, sem rigor científico ou apuro técnico, solicitados a serem realizados em curto período, baseados, frequentemente, em apenas uma entrevista; ou seja, que o exame é mal feito.

\section{$O$ argumento estrutural/institucional:}

Nossas prisões não cumprem o que está previsto pela LEP. São corriqueiras as denúncias de superlotação, alimentação insuficiente ou de péssima qualidade, mau estado das instalações e estruturas. Poucos presos têm acesso a advogados particulares e pela falta de assistência jurídica, ou pela lentidão da Justiça brasileira, acumulam-se 
casos de presos provisórios que aguardam sentença por anos (ROSSOTTI; BICALHO, 2012); muitos continuam em regimes fechados com direito à progressão de regime e existem daqueles que continuam presos mesmo após o término da pena. Há uma imensa defasagem entre o número de profissionais que prestam assistência de saúde em relação ao número de presos, apesar das condições insalubres a que estão cotidianamente submetidos. São poucas as unidades que oferecem algum tipo trabalho ou educação, com o agravo de que a distribuição das vagas insuficientes à população prisional - é majoritariamente realizada segundo critérios de disciplina e favorecimento institucional. Para completar o quadro, denúncias constantes de tortura, violência e maus tratos individuais e coletivos por parte da instituição ou mesmo pelos próprios presos transformam o sistema carcerário brasileiro em um depósito humano caótico, destinado à exclusão e ao puro castigo (KOLKER, 2004).

Nessas condições conclui-se que as prisões, longe de serem instituições destinadas à reinserção do social do sentenciado, transformam-se em espaços de pura segregação social, possibilitando toda sorte de degradações, estimulando a reincidência criminal e oportunizando toda espécie de desumanidade. Diante deste quadro já conhecido, qual é o papel do exame criminológico no percurso da execução penal de um preso que habita tais condições? Em estabelecimentos que não cumprem seu papel institucional, como avaliar o mérito individual do sentenciado e como transformá-lo em critério de não-concessão de um direito, em ocasiões nas quais os mesmos deixam de ostentá-lo para progressão de pena?

A alegação que as cadeias são desumanas e não cumprem seu papel ressocializador parece afirmar que aqueles que criticam a realização do exame criminológico buscam, mais uma vez, reforma e melhorias para o sistema penitenciário. Contudo, a recente criação, no cenário nacional, de presídios federais 12 de segurança máxima e o estabelecimento de Parcerias Público-Privados (PPP) que criaram o primeiro presídio privado do Brasil (SACCHETTA, 2014), em Ribeirão das Neves/MG, apontam que tal argumentação cai em descrédito quando percebemos que nestes presídios não há superlotação: as celas são individuais no Sistema Penitenciário Federal e de até no máximo quatro presos no presídio de Neves. Os presos têm garantida a maior parte de suas assistências (material, saúde, religiosa e jurídica), não há defasagem de funcionários em relação ao número de presos e há, em maior frequência, oferta de trabalho e estudo. A princípio, estas instituições-modelo se adequam ao que está preceituado na LEP, mas ainda mantêm violações relativas à "proporcionalidade na distribuição do tempo para o trabalho, o descanso e a recreação" (BRASIL, 1984, art. $41, \mathrm{~V})$, devido ao elevado tempo de encarceramento que a maior parte dos presos está destinada (em torno de 22 horas dentro da cela ao dia). Nem todos conseguem acesso ao trabalho e estudo, estando submetidos a um con-

${ }^{12}$ Para maior conhecimento do assunto, consultar Reishoffer e Bicalho (2013). junto de regras e disciplinas que transformam o mérito individual em procedimentos que revelam a submissão às regras do cárcere.

Além disso, o perfil selecionado para estar nessas prisões é restrito a alguns internos que possuem uma qualificação determinada. Neste ponto, Presídio Federal e Prisão Privada se distinguem: enquanto nas unidades federais idealiza-se o puro isolamento e neutralização de supostos chefes de organizações criminosas e indisciplinados do sistema estadual; nas prisões privadas, o que importa é selecionar bem para garantir a eficácia do projeto e manutenção dos lucros do negócio, como afirma em entrevista, o subsecretário de Administração Penitenciária do Estado de Minas Gerais, Murilo de Andrade:

Nos estabelecemos inicialmente o critério de que [pode ir para a PPP] qualquer preso, podemos dizer assim, do regime fechado, salvo preso de facção criminosa - que a gente não encaminha pra cá - e preso que tem crimes contra os costumes, estupradores. No nosso entendimento esse preso iria atrapalhar o projeto (SACCHETTA, 2014).

Mais do que qualquer avaliação sobre a possível reinserção social e possibilidades de uma vida digna em liberdade, o exame criminológico - nestes presídios que cumprem em sua maior parte a LEP - não atende a nenhum critério de transformação positiva do encarcerado pelo cárcere. Ao contrário, o exame criminológico só serve para manter e defender a ordem institucional e os princípios de marketing e propaganda de eficácia institucional de ambos.

Nos presídios particulares, as vagas ao trabalho são ofertadas geralmente em ocupações que visam a manutenção do próprio presídio: pintores, cozinheiros, eletricistas, faxineiros. No caso das prisões federais de segurança máxima, são ocupações que dificilmente encontrarão aproveitamento profissional no mercado de trabalho em liberdade e parecem servir mais para ocupação do tempo ocioso do que à aprendizagem de um ofício: costura de bolas, fábricas de estopa, montagem de brinquedos, etc. Assim, o comportamento do preso será avaliado segundo os critérios que defendem a "verdade da instituição", seja uma prisão de segurança máxima e rígida disciplina, seja ela obrigada a gerar números e resultados para maiores investimentos e lucros. A seleção para ocupar estas vagas de trabalho também segue o princípio das prisões tradicionais, em que são geralmente selecionados aqueles que possuem características colaboracionistas com a instituição ou adequação a um regime disciplinar que pouco dialoga com as regras sociais que serão encontradas "extramuros". Como nos diz, mais uma vez, Rauter (2003, p. 104): "O fato de um preso trabalhar no cárcere diz pouco sobre suas possibilidades de reinserção social e muito sobre sua situação no jogo de poder institucional".

Mesmo nas prisões consideradas atentas aos direitos dos presos, o mérito do sentenciado no momento de seu exame que visa à progressão de regime continua sendo a manutenção da máquina carcerária. $\mathrm{O}$ preso de bom comportamento é aquele que atende aos requisitos que são impostos pela disciplina da cadeia, opta por participar de todas as propostas de estudo e trabalho que lhe são oferta- 
das, mesmo que careçam de sentido profissionalizante, pois este sabe que sua recusa, suas tentativas de oposição ou de revolta se tornam diagnósticos de desinteresse, subversão e descontrole, gerando obviamente pareceres "desfavoráveis”. Assim, aparece clara a função do exame criminológico na avaliação dos sentenciados, segundo seu mérito: defender e manter a lógica de exclusão social através da máquina carcerária. O psicólogo como "bom funcionário do cárcere" respalda e atesta o preso que se submete, aceita as condições impostas e não se revolta contra a instituição penitenciária, por mais desumana e aterradora que ela seja. O preso bem-comportado é aquele que nada mais sabe fazer do que obedecer e perpetuar a rotina do cárcere. "É aquele preso que reúne em si a contradição de ser um ótimo preso, imprestável, porém para a vida extramuros, onde teria novamente que lutar por si próprio, algo que há muito desaprendeu" (RAUTER, 2003, p. 106).

\section{O argumento técnico/científico:}

Os magistrados, no exato momento em que solicitam a realização de um exame criminológico com intenção de obter subsídios para suas decisões, ou depositam uma crença hipócrita na eficácia da prisão como instrumento de ressocialização ou apostam em seu total fracasso e inutilidade aguardando que o sujeito tenha se regenerado a despeito das condições impostas pelo Estado. Ao juiz importa estar amparado por alguma técnica ou ciência específica que possa assegurar que o preso realmente "ressocializou-se", que as situações que o levaram a delinquir foram circunstancias ou que sua personalidade possa ter sido modificada com a experiência do cárcere (pela reflexão, pelo sofrimento, pela intimidação, pela disciplina - e, quem sabe, pelas práticas de tortura). Bem como, no caso de um parecer negativo, que estejam comprovadas por um olhar especializado que o sentenciado não apresentou o mérito de progredir para um regime mais brando, seja por atos de indisciplina institucional, seja por seus antecedentes de reincidência, seja pela manutenção de certo status criminoso ou por sua suposta periculosidade.

Outra crítica que nos parece trazer uma falsa questão são os critérios técnicos/científicos que a prisões não fornecem a seus especialistas. São denúncias de defasagem de profissionais em relação ao número de presos, prazos curtos e enorme de quantidade de pareceres a realizar, limitação de entrevistar apenas uma vez o preso e determinar naquela entrevista seu parecer; a publicação a terceiros dos resultados dos laudos, já que tais pareceres entram no processo e se constituem como provas, recebendo o sentenciado, caso tenha advogado, uma cópia daquela avaliação que pode ter resultado em mais alguns anos de prisão. Nestas condições, contestam-se os exames dizendo que são lacônicos, imprecisos, que se configuram uma série de "achismos"; em suma, que são mal feitos, pois não há condições adequadas.

A crítica é mal formulada porque por trás desta suposta "crise" que atravessa o exame criminológico há uma verdadeira eficácia que o mantém: o exame serve e sempre serviu, juntamente com a prisão, para rotular e estigmatizar de forma definitiva uma classe bem de- finida de criminoso. Ora, se já vimos anteriormente que o exame serve para colocar em funcionamento a máquina carcerária, ele é um dos pilares que executa o papel da prisão em nosso sistema: definir a delinquência, uma forma separada e controlada de criminalidade, que deve fazer confundir crime e pobreza. Revestidos de procedimentos com certo grau de cientificidade, buscando assim seu grau de confiabilidade, as avaliações recorrem ao passado da massa carcerária e encontram por lá uma série de variáveis que presumem serem as causas e determinantes para o crime ou sua reincidência. Em suma, os exames técnicos reproduzirão uma série de estereótipos e preconceitos que permeiam os processos de criminalização de nossa sociedade, que atestam que os criminosos e perigosos são os jovens, os pobres e os negros.

A seletividade penal que tem sua força no encarceramento maciço de jovens, negros, pobres e excluídos do mundo do trabalho alimenta determinismos cegos, mecânicos e simplistas que caracterizam os exames. $\mathrm{O}$ exame poderia ser realizado por um número superior de profissionais, com tempo suficiente e técnicas disponíveis, com a ocultação dos resultados que tanto almejam alguns técnicos, mas ele se manteria criticável por basear-se na suposta "essência criminosa" positivista, que busca resgatar dentro do discurso do preso um passado de carências familiares, miséria, início da vida laborativa ainda na infância, afastamento da escola, separação precoce dos pais, uso de drogas, passagem por instituições socioeducativas, 13 abuso de álcool ou outras drogas na família, ambições materiais incompatíveis com sua realidade financeira. Este processo de reconstrução da história objetiva acaba por confirmar através de um pensamento positivista e causalista que estamos diante de uma série de acontecimentos que, analisados isolada ou conjuntamente, poderiam ter produzido um criminoso. "Circula-se tautologicamente sobre este tipo de raciocínio: se tenho diante de mim alguém que está preso e condenado, este alguém só pode ser criminoso e como criminoso, só pode ter história de criminoso" (RAUTER, 2003, p. 91). Atrelado à história individual, o exame criminológico não consegue se desvincular do passado biográfico e passar a focalizar suas avaliações para a seletividade penal presente nos âmbitos judiciários que elegem os crimes praticados pelas classes marginalizadas como alvo preferencial de intervenção penal pela pena privativa de liberdade.

Tais avaliações criminológicas se tornam o momento em que o cárcere se alia ao modelo neoliberal do capitalismo para excluir e estigmatizar as parcelas pobres da população. "Para esta população pobre, que foi destituída da cidadania possível, será adotada a potencialização de sua marginalização social através do controle penal, principalmente da malha carcerária" (REISHOFFER; BICALHO, 2013, p. 172). O modelo de ressocialização fracassou, há reconhecimento da maior parte dos estudiosos da criminologia e até do senso comum de que a prisão não pode ressocializar ninguém, mas unicamente neutra-

\footnotetext{
${ }^{13} \mathrm{~A}$ passagem por instituições socioeducativas constitui elemento negativo presente em qualquer biografia de um preso no momento da avaliação. É o Estado atestando sua própria capacidade criminógena através de suas instituições.
} 
lizar; que a pena de prisão para o sujeito que cometeu um crime não significa em absoluto uma oportunidade de reintegração à sociedade, mas um sofrimento imposto unicamente como castigo (BARATTA, 1990). Diante disso, um laudo com parecer negativo tem por finalidade estigmatizar aqueles que representam uma suposta ameaça permanente a uma sociedade através de suas "histórias de criminosos": a associação entre a pobreza e o crime.

Para piorar a situação ainda nos deparamos, no ano de 2003, com a defesa de uma tese de doutorado na Universidade de São Paulo (USP) pela psiquiatra Hilda Morana (2003), que traduziu e validou a chamada "Escala Hare PCL-R - Psychopathy Checklist Revised" para seu uso no Brasil. Tal instrumento serviria para averiguar o grau de psicopatia presente na população carcerária por meio de uma entrevista semiestruturada "confiável e válida", se "afirmando como instrumento científico capaz de apontar futuras reincidências criminais e, desse modo, definir condições de regressão ou progressão da pena para indivíduos a partir de seu suposto grau de psicopatia" (CÉSAR; SILVA; BICALHO, 2013, p. 361-362). Para a autora da referida tese, estaria sendo ofertado aos técnicos que trabalham nos sistemas carcerários um instrumento econômico e objetivo, capaz de medir se o apenado é um psicopata e em que grau, sempre destacando a incurabilidade destes (RAUTER, 2007). Para os psicopatas, não é possível nem sequer pensar em ressocialização, bastando unicamente a pena de prisão, pelo maior tempo que for possível um juiz conceder. Pura rotulação e estigmatização que só serve para ampliar os níveis de encarceramento através de um instrumento que (re)produz estereótipos e preconceitos ligados à temática criminal.14

Argumentar que os exames técnicos são mal feitos, lacônicos e imprecisos, constituindo-se como meras cópias sucessivas devido à grande quantidade de solicitações é tornar-se cego para o grau de eficácia e de utilidade que os mesmos carregam: definem o futuro de milhares de sentenciados pelo Brasil, marcam de forma indelével alguns como irrecuperáveis, colocam em funcionamento a máquina carcerária em sua função de controle diferencial da pobreza (SCISLESKI et al., 2012), tudo isso em um cenário penitenciário que já abdicou das supostas propostas de ressocialização do preso e fortalece a cada dia suas funções de neutralização e exclusão.

\section{Conclusão}

A partir da Resolução 12/2011, parece que o ponto principal acerca da discussão sobre a proibição ou não em realizar o exame criminológico encontrou um ponto de convergência em separar, em termos operacionais, um psicólogo considerado de assistência/referência e um outro destinado apenas à perícia. Em termos profissionais, em alguns espaços tal resolução pode ter se configurado como uma abertura de novos postos de trabalho e a possibilidade de novos espaços de atuação ao prever em texto legal atividades de assistência à saúde e referência psicológica afastadas da prática pericial. Contudo, sabemos que na maior parte dos estabelecimentos, o que ocorreu foi a divisão do

${ }^{14}$ Para uma análise mais aprofundada dos critérios de validação e quantificação do teste mencionado, conferir Yamada (2009). trabalho entre os psicólogos já existentes no quadro funcional e maior responsabilização com laudos e pareceres aos profissionais destinados apenas à área pericial.

O psicólogo desempenha, a partir da realização dos pareceres técnicos, papel importante na operacionalização da máquina carcerária em seus dispositivos de sujeição e controle dos presos pelo sistema penal. Os critérios escolhidos e os efeitos que precisa identificar estão definitivamente atrelados ao regime de ordem e disciplina das prisões, que serão os mesmos que contribuirão para atualizar, expandir e perpetuar os efeitos mortificadores do cárcere. $\mathrm{O}$ indivíduo dentro de uma sociedade disciplinar e, mais especificamente, dentro de seu aparelho mais característico - a prisão - deve ser moldado, submetido, deve fazer da "verdade da instituição" a sua própria verdade para assim ser classificado como normal ou reabilitado. A supremacia dos objetivos institucionais em detrimento das vontades individuais do encarcerado é o princípio a partir do qual o comportamento deste será avaliado. As tentativas de se opor à disciplina e à ordem, manifestações de revolta e de descontentamento serão vistas como indícios de "não recuperação" e rotuladas como degeneração. "A colaboração, o respeito às normas e à hierarquia institucional, sim, constituem sinais de normalidade e regeneração" (RAUTER, 2003, p. 101).

A discussão que colocou tanto psicólogos entre si e membros do poder judiciário em uma disputa política de forças, está muito além da realização ou não de um exame para progressão de regime. Discutir se o exame se mantém ou não, torna-se uma questão menor nos debates que visam determinar se a prisão é o modelo ideal de penalidade e qual é sua principal função em nossa sociedade para se manter a tanto tempo em crise e reprodutora de crimes e altos níveis de reincidência. Ao psicólogo sempre estará reservado um local de resistência aos principais efeitos mortificadores da prisão, isso caso seja possível que o mesmo se abstenha do lugar de mera classificação ou função pericial, mas até aí é possível produzir diferenças. O exame criminológico (ou qualquer documento que vise subsidiar decisões judiciais) se mantém, mas é sempre preciso ter em mente que os mesmos estão baseados em princípios positivistas que fortalecem e sacramentam preconceitos e estereótipos que visam ligar criminalidade e pobreza e manter sustentada e justificada as medidas de prisão como controle diferencial e privilegiado do crime.

\section{Referências}

BADARÓ-BANDEIRA et al. Resgate histórico da Psicologia no Sistema Penitenciário do estado do Rio de Janeiro. Rio de Janeiro: CRP-05, 2006.

BARATTA, A. Ressocialização ou controle social: uma abordagem crítica da reintegração social do sentenciado. 1990. Disponível em: <http://www.juareztavares.com/textos/baratta ressocializacao.pdf $>$. Acesso em: 15 jun. 2014.

BICALHO, P. P. G.; KASTRUP, V.; REISHOFFER, J. C. Psicologia e segurança pública: invenção de outras máquinas de guerra. Psicol. Soc. Belo Horizonte, v. 24, n. 1, p. 56-65, jan./abr. 2012. CrossRef. 
BRASIL. Presidência da República. Casa Civil. Subchefia para Assuntos Jurídicos. Decreto-lei $n^{\circ} 2.848$, de 7 de dezembro de 1940. Código Penal. 1940. Disponível em: <http://www. planalto.gov.br/ccivil_03/decreto-lei/Del2848.htm>. Acesso em: 22 abr. 2015

BRASIL. Presidência da República. Casa Civil. Subchefia para Assuntos Jurídicos. Lei $n^{\circ} 4.119$, de 27 de agosto de 1962. Dispõe sôbre os cursos de formação em psicologia e regulamenta a profissão de psicólogo. 1962. Disponível em: $<$ http://www.planalto.gov.br/ccivil_03/leis/1950-1969/L4119. htm>. Acesso em: 22 abr. 2014

BRASIL. Presidência da República. Casa Civil. Subchefia para Assuntos Jurídicos. Lei $n^{\circ}$ 5.766, de 20 de dezembro de 1971. Cria o Conselho Federal e os Conselhos Regionais de Psicologia e dá outras providências. 1971. Disponível em: <http://www. planalto.gov.br/ccivil_03/leis/L5766.htm>. Acesso em: 12 maio 2014.

BRASIL. Presidência da República. Casa Civil. Subchefia para Assuntos Jurídicos. Lei $n^{\circ} 7.210$, de 11 de julho de 1984. Institui a Lei de Execução Penal. 1984. Disponível em: <http:// www.planalto.gov.br/ccivil_03/leis/L7210.htm>. Acesso em: 23 abr. 2014.

BRASIL. Presidência da República. Casa Civil. Subchefia para Assuntos Jurídicos. Lei $n^{\circ} 10.792$, de $1^{\circ}$ de dezembro de 2003. Altera a Lei $n^{\circ} 7.210$, de 11 de junho de 1984 - Lei de Execução Penal e o Decreto-Lei no 3.689, de 3 de outubro de 1941 - Código de Processo Penal e dá outras providências. 2003. Disponível em: <http://www.planalto.gov.br/ccivil_03/ 1eis/2003/L10.792.htm>. Acesso em: 10 abr. 2014.

BRASIL. Congresso Nacional. Câmara dos Deputados. Projetos de Lei e Outras Proposições. PL 4500/2001. Altera dispositivos da Lei $n^{\circ} 7.210$, de 11 de julho de 1984 - Lei de Execução Penal, sobre o exame criminológico e progressão do regime de execução das penas privativas de liberdade e dá outras providências. 2001. Disponível em: $<$ http://www.camara.gov. br/proposicoesWeb/fichadetramitacao?idProposicao=27689>. Acesso em: 12 abr. 2014.

CARDOZO, M. A. A. O exame criminológico à luz da jurisprudência do STJ.2010. Disponível em: <http://jus.com.br/ artigos/14224/o-exame-criminologico-a-luz-da-jurisprudenciado-stj>. Acesso em: 10 abr. 2014.

CÉSAR, J. M.; SILVA, F. H.; BICALHO, P. P. G. O lugar do quantitativo na pesquisa cartográfica. Fractal: Revista de Psicologia, Niterói, v. 25, n. 2, p. 357-372, maio/ago. 2013. Cross ${ }^{\text {Ref }}$

CONSELHO FEDERAL DE PSICOLOGIA. Profissão Psicólogo - Legislação e Resoluções para a prática profissional. Brasília: CFP, 2007.

CONSELHO FEDERAL DE PSICOLOGIA. CFP suspende efeitos da Resolução CFP $n^{\circ}$ 009/2010 por seis meses; Resolução $n^{\circ} 010$ é mantida. 2010a. Disponível em: <http://site. cfp.org.br/cfp-suspende-efeitos-da-resoluo-cfp-n-0092010por-seis-meses-resoluo-n-010-mantida/>. Acesso em: 5 abr. 2014.

CONSELHO FEDERAL DE PSICOLOGIA. Resolução 09/2010. 2010b. Disponível em: <http://site.cfp.org.br/wpcontent/uploads/2010/07/resolucao2010_009.pdf>. Acesso em: 20 jan. 2015.
CONSELHO FEDERAL DE PSICOLOGIA. Resolução 12/2011. 2011. Disponível em: <http://site.cfp.org.br/ resolucoes/resolucao-n-0122011/>. Acesso em: 11 jan. 2015.

CONSELHO FEDERAL DE PSICOLOGIA. Suspensão da Resolução CFP $N^{o}$ 10/2010. 2012. Disponível em: <http:// site.cfp.org.br/nota-sobre-a-suspensao-da-resolucao-cfpno-102010/>. Acesso em: 23 set. 2014.

CONSELHO FEDERAL DE PSICOLOGIA; MINISTÉRIO DA JUSTIÇA. Diretrizes para atuação e formação dos psicólogos do sistema prisional brasileiro. Brasília: CFP, 2007.

CONSELHO REGIONAL DE PSICOLOGIA-RJ (CRP-05). Moção contra o Exame Criminológico. 2009. Disponível em: $<$ http://www.anadep.org.br/wtk/pagina/materia?id=4746> Acesso em: 11 abr. 2014.

CONSELHO REGIONAL DE PSICOLOGIA-SP (CRP06). Histórico das ações quanto à Resolução CFP 009/10 e 012/11. 2011. Disponível em: <http://www.crpsp.org.br/ sistemaprisional/acoes.aspx>. Acesso em: 17 maio 2014.

CONSELHO REGIONAL DE PSICOLOGIA-PR (CRP-08). Informativo Trimestral. Revista Contato, Curitiba, ano 13, n. 72, nov./dez. 2010.

FOUCAULT, M. Vigiar e punir: história da violência nas prisões. Petrópolis, RJ: Vozes, 1997.

FOUCAULT, M. Dos suplícios às celas. In: MOTTA, M. B. da (Org.). Segurança, penalidade e prisão. Rio de Janeiro: Forense Universitária, 2012. v. 8, p. 32-36. Coleção Ditos \& Escritos.

KOLKER, T. A atuação dos psicólogos no sistema penal. In: BRANDÃO, E. P.; GONÇALVES, H. S. (Org.). Psicologia jurídica no Brasil. Rio de Janeiro: NAU, 2004. p. 157-204.

MARCÃO, R. $O$ exame criminológico e a equivocada Resolução n. 9/2010 do Conselho Federal de Psicologia. 2010. Disponível em: <https://jus.com.br/artigos/17072/oexame-criminologico-e-a-equivocada-resolucao-n-9-2010-doconselho-federal-de-psicologia>. Acesso em: 20 abr. 2014.

MECLER, K. Periculosidade: evolução e aplicação do conceito. Rev. bras. crescimentodesenvolv. hum., SãoPaulo, v.20, n. 1, p.7082, abr. 2010. Disponível em: <http://pepsic.bvsalud.org/scielo. php? script=sci_arttext\&pid=S0104-12822010000100010>. Acesso em: 12 jan. 2015.

MORANA, H. Identificação do ponto de corte para a escala PCL-R (Psychopathy Checklist Revised) em população forense brasileira: caracterização de dois subtipos de personalidade; transtorno global e parcial. 2003. Tese (Doutorado em Psiquiatria)-Faculdade de Medicina, Universidade de São Paulo, São Paulo, 2004. Cross ${ }^{\text {Ref. }}$

RAUTER, C. Criminologia e subjetividade no Brasil. Rio de Janeiro: Revan, 2003.

RAUTER, C. Clínica e estratégias de resistência: perspectivas para o trabalho do psicólogo em prisões. Psicologia e Sociedade, Porto Alegre, v. 19, n. 2, p. 42-47, maio/ago. 2007. Cross ${ }^{\text {Ref. }}$

REISHOFFER, J. C.; BICALHO, P. P. G. O Regime Disciplinar Diferenciado e o Sistema Penitenciário Federal: a reinvenção da prisão através de políticas penitenciárias de exceção. Polis e Psique, Porto Alegre, v. 3, n. 2, p. 162-184, 2013. Disponível em: $\quad<$ http://seer.ufrgs.br/index.php/PolisePsique/article/ view/43094>. Acesso em 14 maio 2014. 
REISHOFFER, J. C.; BICALHO, P. P. G. A circunscrição histórica das prisões e a crítica criminológica. In: FARIAS, F. R.; FACEIRA, L. S. (Org.). Punição e prisão: ensaios críticos. Rio de Janeiro: Lumen Juris, 2015. p. 13-26.

ROSSOTTI, B. G. P. P.; BICALHO, P. P. G. Por uma outra psicologia no cárcere: presos provisórios, processos de criminalização e produção de subjetividade. In: MARTINS, S.; BEIRAS, A.; CRUZ, R. M. (Org.). Reflexões e experiências em Psicologia Jurídica no contexto criminal/penal. São Paulo: Vetor, 2012. p. 81-108.

SACCHETTA, P. Quanto mais presos, maior o lucro. Carta Capital, 28 maio 2014. Disponível em: <http://www. cartacapital.com.br/sociedade/quanto-mais-presos-maior-olucro-3403.html>. Acesso em: 20 jun. 2014.

SCISLESKI, A. C. C. et al. Juventude e pobreza: a construção de sujeitos potencialmente perigosos. Arquivos Brasileiros de Psicologia, Rio de Janeiro, v. 64, n. 3, p. 19-34, dez. 2012.

SILVA, H. C. O exame criminológico e a oportuna Resolução no 9/2010 do Conselho Federal de Psicologia. 2010. Disponível em: < < <ttp://www.conamp.org.br/pt/biblioteca/artigos/ item/529-o-exame-criminologico-e-a-oportuna-resolucao-n-92010-do-conselho-federal-de-psicologia.html>. Acesso em: 12 jan. 2015.

YAMADA, L. T. O horror e o grotesco na psicologia: avaliação de psicopatia através da Escala Hare - PCLR. 2009. Dissertação (Mestrado em Psicologia)-Programa de Pós-Graduação em Psicologia, Universidade Federal Fluminense, Niterói, 2009.

Recebido em: 3 de março de 2015 Aceito em: 7 de julho de 2016 